ENSAYO

\title{
DEFENSA DE CERVANTES CONTRA DETRACTORES Y ENTUSIASTAS*
}

\section{Luis Chitarroni}

Frente a las eternas (y exageradas) disputas entre entusiastas y detractores del Quijote, el autor intenta iluminar algunos aspectos del texto cervantino desde la mirada de Jorge Luis Borges, presente en su célebre relato "Pierre Menard, autor del Quijote". Asumiendo las limitantes de la crítica, el artículo aborda temas fundamentales en torno a la novela (como el cuestionamiento de la noción de autor, el estilo y los personajes) a partir de un diálogo, tanto retrospectivo como prospectivo, de ésta con la tradición literaria.

LuIS ChitARroni. Narrador y ensayista argentino (Buenos Aires, 1958). Desde 1980 publica artículos en distintas revistas y diarios. Dirigió talleres de narrativa y de crítica literaria. En 1992 publicó Siluetas, una serie de breves biografías dedicadas a escritores, algunos de ellos imaginarios. En 1997 aparecieron su novela El carapálida y la colección de ensayos Los escritores de los escritores. En colaboración con Raúl Brasca ha compilado las siguientes obras: Antología del cuento breve y oculto; La hora de todos (cuentos de fines de los siglos XVIII, XIX y XX); Antología del cuento extraño latinoamericano y Textículos bestiales. Desde 1986 trabaja como asesor literario y editor de Editorial Sudamericana.

* El título pretende ser un homenaje al título del magnífico ensayo de Theodor W. Adorno, "Defensa de Bach en contra de sus entusiastas". Como el rigor y los conocimientos, y el rigor en alcanzarnos tales rigores y conocimientos, difieren por completo del método que practico en este ensayo, el título adquiere con ironía disculpable el carácter de profanación inherente.

Estudios Públicos, 100 (primavera 2005). 


\section{Introducción}

ntervenir (anticuado en términos artísticos, el verbo simula ser víctima de la moda en una evaluación que lleva años de fragua), parece a la vez tan modesto y arrogante como la mayoría de los actos simbólicos en pro o en contra de algo. Ponerse a la altura de las circunstancias: contra los alardes, una sinopsis; contra las argumentaciones exhaustivas, una serie de sospechas descarriadas que tal vez nos conduzcan a otras zonas, a otros libros, a nuevas reservas, a nuevas sospechas. El tratamiento a la vez convencional y asistemático de las notas al pie, atentas con la misma pusilanimidad a las alusiones recónditas y a las referencias obvias, es una prueba más de mi recelo hacia la "objetividad" académica1. Por lo mismo, las palabras sobre la novela de Cervantes que siguen se jactan de ser más parciales que las magias que supo sustraerle Borges, aunque seguro también menos precisas e inspiradas.

Moverse, ocupar un lugar dentro de la frondosa bibliografía crítica, nos obliga a participar en una batalla en la que nos negamos a dar y a recibir órdenes. O a hacer el papel del aguafiestas profesional, creyendo recibir órdenes estentóreas de tradiciones que nada significan para nosotros, al mismo tiempo que las revocamos o las corregimos para dárselas en falsete a generaciones y vanguardias que ya no nacerán. El único lugar posible de una crítica como la que se ofrece es el de una consonante o, mejor, el de un signo de puntuación acorralado en la selva repetida de la página, donde, como en el mundo swedenborgiano previsto, planeado por William James Senior para desconsuelo de sus dos ilustres hijos, "aúlla el lobo y pontifica el obsceno pájaro de la noche". La perspectiva de una coma, digamos: un signo, una marca casi imperceptible. Oscura, obstinada, misteriosa. Ojalá, dicho con agarena sencillez, encuentren sentido en la página atiborrada en todas las direcciones; algún lugar que celebre los logros del estilo y el genio de la lengua en un mundo habituado con emotiva sumisión a censurarlos.

Detractores y entusiastas

Es fácil advertir a menudo en el elogio de Cervantes, en especial del Quijote, dos operaciones opuestas al curso de su lectura y a las conclusio-

\footnotetext{
${ }^{1}$ La bella beligerancia de las notas al pie ha sido estudiada con apasionamiento por Anthony Grafton. Buen pretexto para hacerlo saludar a cámara desde aquí abajo. Por obediente que pueda parecer hoy el uso de las notas al pie en cualquier artículo o texto crítico, buscaremos justificar este ejercicio de ida y vuelta del lector con algo más que una comprobación o la transcripción de una fuente.
} 
nes que cualquier lector puede sacar. La primera es la simplificación; la segunda, la tolerancia injustificada ante los excesos caudalosos de esta caudalosa obra maestra. La última parece estar en concordancia con el bello elogio de uno de los modernos - modernistas - lectores del libro, Rubén Darío, quien en su "Letanía de nuestro señor Don Quijote" pudo agotar la ordenada serie deficiente. Ésta elige motivos siempre dignos de una legítima defensa, y levanta la vitalidad admisible y admitida de los personajes de la novela contra las cerradas consideraciones, generalmente académicas y muertas de los exégetas. Lo mismo da que escoliastas y comentaristas sean detractores o exaltadores: es la grisura teórica la que impide la verde manifestación de los frutos verdaderos de Don Quijote, la cruzada personal de este personaje que resigna su heroísmo a una época en donde la verdad y la mentira son canjeables, ya que la adarga las embestirá de manera indistinta ("contra la mentira, contra la verdad"). Es verdad que la verdad crítica de Darío depara al menos una sorpresa que la crítica española — entre Menéndez y Pelayo y Menéndez Pidal - escamoteaba todavía con prodigiosa y prolija prudencia: "el ingenio lego" demostraba la ventaja que les había sacado a sus contemporáneos - el Siglo de Oro todo, Mateo Alemán incluido- con su voluntario arcaísmo, su amor por el pasado, su desconfianza por los latidos del presente, por la transformación de ese presente en sustanciosa literatura. De esa hoy detectable actitud, el modernista Darío infería - detectable también hoy- la modernidad incipiente e informal, intransferible del personaje y el libro.

Se ofrece así, sin discriminación porque, con ánimo de ofender el tan detractado presente, ¿a quiénes llamaremos detractores y a quiénes entusiastas?, con presteza y sin ánimo de abundar en paradojas se averigua que no es difícil que los alineados pasen a integrar la otra lista apenas se rasga la superficie. Pero los valores múltiples merecían seguramente una suerte distinta y distraída de la repetición marcial de estos méritos incuestionables. La primera operación de la que hablamos precisa el nudo restrictivo inherente al ciclo de las evaluaciones engañosas.

El hecho de que veamos hoy en la novela de Cervantes el repertorio completo de los recursos y posibilidades de la novela no es óbice para revisar el empleo de algunos; el acto seguido de exaltarlo o deplorarlo pertenece - de acuerdo con el canon de Menard - al demorado y preterido oficio de la crítica literaria. La lista de entusiastas y detractores de Don Quijote se limita a la cantidad exigua que permitió el trabajo de campo y el poder de observación de quien escribe. Los nombres son demasiados. Bástenos los obvios en breve visita que el lector encontrará en las notas: los argumentos de unos y otros se compulsan, se revelan, se relevan, se con- 
tradicen. Dos, en particular, parecen haber sido programados para disentir sin encontrarse jamás en la órbita de su tiempo, de acuerdo con una armonía preestablecida emponzoñada. Son Paul Groussac y Américo Castro ${ }^{2}$. El primero, majestuoso docente, derrama sobre la ignorancia geográfica y líquida de Cervantes un archipiélago sólido de iniquidades que complacerá a otros lectores ávidos de flaquezas dignas de sus aparatos digestivos. El último justifica cada flaqueza con una obesa argumentación que no ha logrado sino un solo exégeta. Uno sostiene que Miguel de Cervantes es hijo de cristianos viejos, circunstancia no desmentida por el hecho (registrado con una ironía de barítono) de que quienes atestiguaron esa antigüedad hayan sido personas que los conocieron apenas unos meses antes. El otro no tiene dudas de que es un cristiano joven, como lo atestigua la obstinación por hacer méritos de Miguel de Cervantes y, contrario sensu, la incapacidad casi recíproca para obtener premios y sinecuras. Uno averigua sin evidencias que Cervantes y Mateo Alemán se conocieron —y más, que hablaron sobre sus obras respectivas - en asiduas y respectivas jaulas y ergástulas (tal vez estas fórmulas contenciosas tengan como resultado o solución la esticomitia y el diálogo). El otro infiere que el primero ha leído al último —o por lo menos la parte primera del Guzmán de Alfarache— por una cita que es un plagio y por la tranquila ausencia de Mateo Alemán (que da como prueba indudable de admiración) en El viaje del Parnaso. Los dos son precisos, verbosos, incansables. Los dos, cuando se los instiga, traen a la contienda todas sus insignias. No imagino prisión, cautiverio, presidio capaz de encausarlos, de mitigar la perpleja tarea de iluminarnos con la razón que ambos se impusieron.

\section{Tenues avisos espirituales}

"Il semble que les gitans et les gitanes ne sont nés au monde que pour être larrons: ils naissent de pères larrons, sont élevés parmi de larrons et, finalement, parviennent à être des parfaits larrons en toute circonstance.” ¿Qué lector de la literatura argentina que se precie —o que curse la carrera de Letras en la UBA - no reconoce en este comienzo la influencia de "El niño proletario", de Osvaldo Lamborghini, recientemente traducido al francés? "Desde que comienza a dar sus primeros pasos en la vida, el niño

${ }^{2}$ Aunque ambos no tardarán en reaparecer, podemos darnos el gusto de despacharlos en una sola nota. Los libros consultados fueron: J. J. Borges, Jorge Luis Borges selecciona lo mejor de Paul Groussac (Buenos Aires: Editorial Fraterna, 1981), y Américo Castro, Cervantes y los casticismos españoles, edición al cuidado de Paulino Garagorri (Madrid: Alianza, 1974). 
proletario sufre las consecuencias de pertenecer a la clase explotada. Nace en una pieza que se cae a pedazos, generalmente con una inmensa herencia alcohólica en la sangre. Mientras la autora de sus días lo echa al mundo, asistido por una curandera vieja y reviciosa, el padre, el autor, entre vómitos que apagan los gemidos lícitos de la parturienta, se emborracha con un vino más denso que la mugre de su miseria"3. El mismo determinismo temperamental, la misma determinación estilística. Cierto que el francés, más circunflejo y mesurado, se afeitó esa mañana: evita el regodeo cadencioso en las circunstancias físicas, omite con elegancia genérica lo meramente descriptivo de la definición o lo sustituye por la medida repetición anafórica. Esto se debe en gran escala a la superioridad cultural del precursado sobre el precursor; pero a pesar de esos énfasis diversamente administrados, la violencia discriminatoria es la misma.

Veamos el indócil original español que deparó la traducción francesa: "Parece que los gitanos y gitanas solamente nacieron en el mundo para ser ladrones: nacen de padres ladrones, críanse con ladrones, estudian para ladrones, y finalmente salen con ser ladrones corrientes y molientes a todo ruedo, y la gana de hurtar y el hurtar son en ellos como accidentes inseparables, que no se quitan sino con la muerte". Ahora, las partes parecen acercarse. Un estilo abusa en la misma lengua de lo que queda de la precedente. La traducción francesa, parsimoniosamente literal, lo es hasta donde el mejor ritmo francés lo deja, hasta ese "en toute circonstance" que redondea y modera a la vez el párrafo y se rehúsa a seguir retorciendo la sintaxis con dosis ajenas a la buena conducta idiomática. Pero el español es mucho más atrevido y "moderno". Y cuando incorpora la siguiente proposición después del asíndeton, proyecta ya una abstracción tutelar - "accidentes inseparables"- que permite completar la órbita, terminar con el fin último.

El español original es Cervantes, La gitanilla, una de las novelas ejemplares que no sabemos si el genio lego escribió en esos años pero que publicó entre las dos partes del Quijote 4 . El juego que permite hacer la perspectiva histórica, distorsión o aberración del ojo en dirección al pasado, a la falta de soluciones que nos brinda ser una consonante o una coma, es un plagio: un remedo de la lectura ejemplar que Borges hiciera de Cervantes, publicada en la revista Sur en 1939, "Pierre Menard autor del Quijote". En él

${ }^{3}$ Osvaldo Lamborghini, "El niño proletario", en Novelas y cuentos (Barcelona: Ediciones del Serbal, 1988).

${ }^{4}$ Detengámonos primero en la versión francesa supracitada, que mantuvimos en suspenso hasta que se aclarara el misterio. Es La petite gitane, traducción, introducción y notas de Michel Lafon (France: Aubier/Domaine Hispanique, 1994). En cuanto a las Novelas ejemplares, Miguel de Cervantes Saavedra (Buenos Aires: Losada, 1942). 
se entreveran razonamientos que nos permiten entender la lógica extrema de esos "tenues avisos espirituales" que trascienden la falsa atribución.

Hay que entender al narrador de Borges "en toute circonstance" para advertir que no está en peligro la propiedad intelectual - o por lo menos no sólo ella — sino algo más recóndito y misterioso — más próximo al atem, al hálito, al soplo divino de los místicos-, y reordenar el cuento de Borges, así como la novela de Cervantes, en su verdadera dimensión, para que el juego haga peligrar algo más que las pequeñas certidumbres con las que lectores y críticos nos conformamos. Porque, equivocándonos desde el vamos, el narrador de Borges es o podría ser un joven bastante frívolo de la action française, contemporáneo, digamos, de Lucien Rebatet, que admira profundamente a Menard y no se deja distraer de la preciosa lista (que constituye la "obra visible" de Menard, obra que puede ser enumerada hasta la letra $s$, curiosamente). Un proto Proust fatuo, furtivo, infantil, que patrulla la literatura con esas dos debilidades que se agrandan y se agravan con la mayoría de edad: la ironía y la política adjetival.

Pero el cuento trata de otra obra, de la "invisible". Y ésta es más una tarea irrealizable que un libro propiamente dicho, un obstinarse sin límites en la imposibilidad hasta devolverle a la materia un sustrato conceptual. Algo parecido al Livre mallarmeano, tal vez con justificativos prosaicos menos codiciosos. Aclaremos, como aclara el narrador de "Pierre Menard autor del Quijote", que Menard no quiere escribir un tributo ni un libro imitativo de la novela de Cervantes - ese proyecto que tanto éxito ha tenido en diversas literaturas, de Tartarin de Tarascon, la Donna Quixote de Gerhardie al Monseñor Quixote de Graham Greene- sino El Quijote, el verdadero Quijote. Para lo cual encuentra una dificultad que no parece afectarlo: El Quijote, el verdadero Quijote ya ha sido escrito. Y lo ha escrito un español muy poco parecido a él "en toute circonstance".

Ese español había nacido en Alcalá de Henares, combatido a los moros, padecido la cárcel. Su profesión más honrosa, alcabalero, cobrador de deudas, no pudo mitigar - acaso sólo propiciar - la creación de un caballero, cuya obligación primera es, según Quevedo, "contraer deudas". ¿Qué tiene que ver con él, Menard, civil solvente aunque no acaudalado, heredero de una renta, de una propiedad sólida, de una biblioteca primero enriquecida y luego puesta a dieta por esos "accidentes inseparables", la gana y el hurto, de lateralidad intacta? Pierre Menard está entero, sin heridas de guerra ni guerras sino de oídas. Mastín fausto, algo remolón.

A Cervantes pudieran dominarlo, cuando comenzó el Quijote, las desazones que le depararon sus no muy reputadas incursiones en la poesía y el teatro. Ante él, Menard es un triunfador. Para no ser copiosos, báste- 
nos mencionar tres victorias: ha refutado a Luc Durtain, ha desmontado la prosodia de Paul-Jean Toulet, ha traducido a Quevedo. Quevedo, a su vez, traductor de Francisco de Sales, estaría en la gloria leyendo que su "Aguja de navegar cultos" (instrucciones precisas para escribir en el dialecto culterano de Góngora) es en la versión francesa de Menard "La boussole des précieux". Siempre hay un Quevedo auxiliar, un Quevedo paralelo. Siempre hay un Quevedo de soslayo. Porque Quevedo es de sombra, como advirtió bien Gómez de la Serna, que oyó o sospechó además que el alma de Quevedo "era una perrera". Porque Quevedo se atrevió a ser su mitad oscura. Lejos de las regalías de Pérez Reverte, que lo convierten en un borracho de insulto fácil, torpe espadachín, Quevedo es siempre un arma de doble filo, el filo de un pensamiento lateral, filoso, filosófico. Que-ve-do: la punta de la lengua esperando dos turnos para poder al fin producir el nombre de una nota musical en clave. Quevedo se anima a representar al Machiavello de la literatura, tarea nada fácil en un territorio de tahúres disfrazados de labriegos cuyos corderos juegan a los dados.

Ahora bien, las tres operaciones triunfales de Menard resultan suficientes para reconocer su ámbito, su milieu. ¿Qué tienen que ver estos dos sujetos para escribir el mismo libro? Pero la pregunta la provoca una falacia conceptual que antepone el autor a la obra. Vale decir: el contexto, la voluntad, la personalidad o la psicología a la palabra. ¿Qué nos hace suponer que un mismo libro sólo puede ser escrito por la misma persona? ¿Qué es ese principio latoso que encadena las obras a los hombres, y éstos a ese lastre que en los muy arrogantes consolida todos los relatos, una señora tuerta atada a un brazo llamada experiencia?

Ventajas de ser manco, o estar in advance of a broken arm.

En una parábola ejemplar —equivalente a los gestos abstraídos y generosos de Marcel Duchamp—, Pierre Menard, su quasi contemporáneo literario, ataca, daña y corrompe la estabilidad cómoda de esa enemiga de la cordura que es la sensatez y nos obliga a releer el Quijote para entender mejor la literatura. Porque hasta entonces, y en manos de exégetas en su mayoría españoles, los valores del libro no parecen ser los mismos que los de las literaturas adyacentes, aledañas, europeas. Dante, Milton, Racine, Corneille. ¿A quién podría ocurrírsele? Menard, espíritu no sólo emparentado con la tradición sino con la moda (debilidad razonable, duplicidad implorante) es quien decide valorar el Quijote, imponerlo contra el face value - Edgar Allan Poe - de esa cultura francesa, ordinaria y receptiva, fashion. Que engendró a Baudelaire, que engendró a Mallarmé, que engendró a Valéry. Fetiches olfativos, modelos retinianos. 
Para ello necesita que hagamos un pequeño esfuerzo, un débil concurso. Porque los dos fragmentos que Menard pudo concluir antes de su muerte son dos condiciones sobre nuestra rendición incondicional: un breve pasaje sobre la historia, cuya madre es la verdad, y un florido discurso acerca de las diferencias entre las armas y las letras, en defensa de las armas.

Ahora bien, la familiaridad con que el narrador se mueve en círculos y cenáculos, su exhibicionismo en el name dropping y alguna que otra imprecisión nos dan la pauta de que el narrador es, como Menard, francés. Pero al cabo de un rato, y causa de ciertas fanfarronadas, advertimos que sólo puede ser un francés en afectación pluscuamperfecta, vale decir un argentino. Como se dijo antes, alguien más inclinado a las competencias técnicas de la literatura que a su práctica, preparándose para olvidar mejor todo. $\mathrm{Y}$ a consumar a todo trapo ese género menor o mayor, de acuerdo con quien lo practique, que Edgardo Cozarinsky denominó, atento a la vulnerabilidad inherente de las mutaciones bruscas, "el relato indefendible": el chisme.

Como empieza a constar en el capítulo IX de la primera parte, el que narra las aventuras del caballero de la triste figura no es sino la traducción de un manuscrito árabe de Cide Hamete Benengeli, que el "Cervantes" actoral del espacioso Don Quijote le hace traducir a un morisco aljemiado. (Este silencioso participante cumple, digamos, la función de Menard, callando, y recuerda al "maronita suplementario" que Borges en "Las traducciones de las Mil y una noches" le hace llevar y traer al atildado Galland.)

No sé si por escrito, pero en algún momento (o en más de uno de los que consentía su a veces imprudente oralidad), Borges el hombre público dijo que "El arte sucede", la frase de Whistler era un facsímil (o una equivalencia laica) del evangélico "el Espíritu sopla donde quiere". Poco después se convirtió en una letanía auxiliar, en una muletilla de la elegante precedencia del apócrifo.

Después de los hechos que la historia se obliga a registrar para reconocerse, atribuir La imitación de Cristo a Mir Bahadur Alí y a Cide Hamete Benengeli El coloquio de pájaros (a Maurice Molho la traducción al español y al francés de las dos obras) es ya una manera de exagerar de qué modo la literatura ha conquistado esa pasión disimulada y superior: la indiferencia. No sólo a las propiedades sino a los prolijos menesteres del conocimiento.

Como Duchamp contra la pintura retiniana (con toda esa bobería represora tranquilamente comunicativa, expresiva), de la que guarda el tufo, trementina (recuerdo proustiano de repudio), y con el mismo desinterés 
pulcro y atontado, Pierre Menard hace un gesto de rechazo por la excesiva (excesivamente ornamental, excesivamente simbolista, excesivamente cenacular, excesivamente exhibicionista) literatura francesa de marras, à la mode. Reconoce un modelo literario. Renuncia a todas esas obras de orfebrería retórica que la literatura francesa derrocha: de Emaux et camées a las Contrarrimes, pasando por Corbiére, Laforgue y Heredia. Contra todas esas extorsiones estéticas, impone un modelo literario inadecuado, precoz, despreciable, conceptual: Cervantes.

Sí, va a ser Borges, precisamente, apaciguador decidido de las alarmas del Doctor Américo Castro y lector diametralmente opuesto a Nabokov (a pesar de las aparentes semejanzas), quien podrá reestablecer una lectura "moderna" de Don Quijote, tan moderna que los especialistas y académicos españoles siguen considerándola, lamentablemente, una boutade.

\section{Estilo}

Groussac habló de "la contextura generalmente desmayada de esa prosa de sobremesa". Bataillon escribe de ella: "si se la compara con los guisos condimentados de Quevedo o de Tirso de Molina, tiene la sabrosa insipidez de la leche o el pan"5.

Sabrosa insipidez, nervioso oxímoron. Leche, pan: alimentos elementales. Naturaleza misma de la cosa descrita de la mejor manera, la más rápida, la inmediata. Porque cuesta mucho saber cómo y de qué hace Cervantes su estilo. No de ingenios reiterados y figuras tomadas del repertorio latino, como hace Quevedo con gracia (en su "Autorretracto", Cabrera Infante denuncia: "Más Quevedo que Cervantes a mi pesar". El estilo no se domina).

Contrariamente a la idea de parodia, en la que alguien se apodera de las maneras de otro, un estilo no puede dominarse. El parodista ejecuta las características que su aritmética emulativa extrajo a costas de una ventaja y un agravio equiparables. Giorgio Colli, disertando sobre los estilos opuestos de Hegel y Nietzsche, llega a la siguiente conclusión: "el estilo debe borrar el condicionamiento concreto, el procedimiento material del individuo racionante. El pensamiento debe presentarse desprendido del modo en que ha sido conquistado, como una realidad en sí misma, sin nada personal."

${ }^{5}$ Marcel Bataillon, Erasmo en España, estudios sobre la historia espiritual del siglo XVI, traducción de Antonio Alatorre (México: FCE, 1950). El libro de Bataillon nos deja una enseñanza notable, que el autor confiesa en el prólogo con incomparable modestia, acerca de los efectos y las causas. Haber estudiado un siglo sólo permite averiguar cuánto nos interesa el anterior. 
La imitación, en tiempos cervantinos, si bien practicada por muchos ("que de otro imitó los modos/ por conocerlos a todos"), es territorio predilecto de Quevedo, que puede desplazarse a sus anchas en el laberinto español con su dicción cargada y sus contenciosos juegos de palabras.

El estilo de Cervantes es el que la novela le pide, ni más ni menos. Porque El estilo no es una máscara sino lo contrario, al paso cansino de Rocinante. La diversidad lo conforma, lo consuela, lo enriquece. Aunque el estilo pida, para su bien, para su satisfactorio sacrificio, para su satisfactoria hecatombe, pobreza, estrechez, inopia, concisión, Cervantes sabe darle eso y su contrario. $\mathrm{Y}$ en realidad, salvo lectores que empiezan siendo adversos, y que en general no son hispanoparlantes de nacimiento - Groussac-, o lo leen traducido - Borges, Nabokov, Amis-, el estilo empieza siendo incantatorio porque hasta hace unos años había sido memorizado como un catecismo: "En un lugar de La Mancha, de cuyo nombre no quiero acordarme...", pero también porque de inmediato ese mundo empieza a funcionar a las mil maravillas, con las dos mujeres de la casa, el rocín flaco y el galgo corredor. Y el menú de Don Quijote, leído con curiosidad por la gracia con la que esas palabras se combinan, se retuercen, se olvidan. Se recuerda luego entero, y luego - y tal vez por obra y gracia de esa gracia que le sobraba al manchego - cobra una significación superlativa. Y no es porque el Guzmán de Alfarache se muera de hambre. Pero los dos estilos —el de Cervantes, el de Mateo Alemán - se complementan sin, a pesar de Américo Castro, oponerse acerca de la concepción del mundo. Renoir decía de Rembrandt: "Él se come toda la carne y yo me quedo oliendo la salsa". No es el caso.

Se dice que Don Quijote es una lectura excelente para el joven lector. Si lo fuera, algo curioso e irrepetible ha ocurrido en la historia de la cultura de Occidente. Don Quijote es una lectura "fácil" sólo cuando se han emprendido otras y éstas han parecido en extremo protocolares o alegóricas: La divina comedia, El paraíso perdido. Si el lector emprendió la lectura de Don Quijote después de éstas, no tiene atenuantes acerca de su inocencia. Llamaremos "inocencia" a la inagotable capacidad de Don Quijote de ir en pos de lo que sigue, sea lo que fuere - andanza, desenlace, percance, moraleja - a despecho de su experiencia. Es casi imposible que otro personaje de la literatura se equipare a Don Quijote en términos de obstinación idealista. Un escritor argentino en un buen día contemplaba la alegre frecuencia con que se "expulsaba la abyecta noción de fracaso". Martin Amis llega a decir que no hay próxima vez en Don Quijote sino sólo más y más ${ }^{6}$, aunque

\footnotetext{
${ }^{6}$ Escribe con soltura, después de terminar la traducción del escocés Tobias Smo1lett: "The question 'what happens next?' has no meaning, because there is no next in Don Quixote's world: there is only more)", Martin Amis, "Broken Lance", incluido en The War Against Cliché: Essays and Reviews 1971-2001 (New York: Tal Miramax Books, Hyperion, 2001).
} 
lo atribuya a un defecto novelesco de Cervantes, no a una característica esencial del personaje. Tener presente que esa obstinación idealista se transforma no implica disminución sino conciencia del valor narrativo de la apuesta, así como la confrontación contra la naturaleza y el contexto reactivan cada vez en Cervantes la invención y el recurso.

Por eso algunas de las lecturas a contrapelo del libro —notablemente la de Nabokov, acaso la única con esa característica en su carrera de crítico- pueden distribuir y equiparar victorias y derrotas como en un torneo de tenis.

Violenta desazón, violento desengaño que instruyen la angostura heroica de un inequívoco campeador del fracaso para sustituirla por el grosor inadvertido de un héroe moderno del azar. Doble triunfo del escritor ruso que repercute como reputación en una mise en scéne biográfica, profesional de la ordalía.

Nabokov lee Don Quijote como Nebrija las Escrituras —o, mejor dicho, como Bataillon en su inmenso libro cuenta que las leyó-, segregando con muy buen tino los realia, con la desventaja superior de que él no tiene las claves idiomáticas para traducirlo. Sin metáfora, lo explicita en sus interdicciones. Entre ellos esos "duelos y requiebros" que el traductor al inglés en cualquier caso desluce ante el ávido inquisidor extranjero. De una al menos de estas características rurales puede establecerse una ley general. Y Nebrija, que estará a sabiendas en Don Quijote, lo estará en el "candeal, trechel y rubión", enigmático y trivial, bíblico en el mejor sentido, confundido con lo que cada uno de los personajes ingiere. El estilo, sí, el estilo.

\section{Locura}

En el "laberinto de errores" (que La Celestina denuncia o celebra) del siglo veinte (y en lo que va del veintiuno), la simpatía por la locura, alejada de cualquier exaltación erasmiana, es una de las efusiones más banales y filisteas que puedan considerarse de pie. No se sabe cómo prosperó esta adherencia gratuita que nada tiene de compasiva, pero lo hizo sin dejar otra huella que una ligera tendencia al sentimentalismo en los peores poetas y una calculada manera de admirar en los adolescentes.

La locura quijotesca, la quijotada, ésta sí con toda su exaltación erasmiana, surge en el siglo dieciocho - mencionada acaso por el Padre Isla - como una singularidad fría, destilada, que conduce los venenos, y que es obra de los mismos. No terminan todavía de decírnoslo detractores y entusiastas de los libros de caballería. Porque siendo el siglo de marras 
todavía un festín de supersticiones y, sobre todo, de fantasías y delirios enraizados en cosas concretas, entre las múltiples opiniones e hipótesis de la locura de Quijano/Quijote (la dualidad pertenece a la inestabilidad entre uno y otro, cuerdo/loco), una da por cierta la exageración de su régimen, en el que podemos contar, entre otras cosas, el salpicón las más noches, los huevos con torrezno los sábados y las lentejas los viernes, tan peligrosas. Aquí se podrían sumar los "duelos y requiebros", uno de los realia sobre los que se detiene Nabokov, y oponerlos tal vez a la ración carcelaria del Guzmán de Alfarache, siempre tan cuerdo. Es difícil discernir si las tantas aventuras de Amadís y Tirant lo Blanc suman más o menos que estos menúes alimenticios, valores diarios... Américo Castro casi transmite la voluptuosidad de estos contrastes, pero de todos modos, la nota de Nabokov es irresistible. Una mezcla de Robert Burton melancólico y dietólogo lúdico, tipo Gayelord Hauser, se conjugan para transmitir la profunda comprensión y antipatía con que un hombre del siglo diecinueve, que se ha robado para sí todos los secretos de la Rusia zarista, espía el siglo diecisiete: "duelos y requiebros" (averigua Nabokov que ha averiguado un traductor, Duffield) es "un guiso hecho con la carne de animales que sufrieron muertes de accidente al caer de precipicios y romperse de esta manera el cuello". Al autor ruso le llama más la atención que el "duelo" no tenga en cuenta el dolor experimentado por las víctimas zoológicas - a fin de cuentas baladíes e inesenciales-, sino por la pérdida sufrida por el pastor o el propietario, apurado, ávido de convertirlas con rapidez en chivitos y corderos humeantes. Este entreacto de lo crudo y lo cocido imita de manera caricaturesca un pacto antropológico caro a los lectores de lengua inglesa, que el taimado Tobias Smollet (1721-1771), novelista y traductor del Quijote, acentuó.

El tema de la locura, por otra parte, es uno de los que ha terminado siendo más "moderno" (piense el lector en otro a quien esta palabra todavía le parecía un modo de comportarse en el mundo con vivacidad y juventud, antes que denigraciones y desengaños tan lúcidos como irrelevantes le hicieran perder la fe). Y hay un modo de admitir que este desvarío laborioso del personaje Don Quijote es una forma estudiada de locura ambulatoria, costumbre a la que tanto caballero inglés y caminante a secas nos ha acostumbrado (y que con especial atención reflejaron John Perceval como paciente predispuesto al estilo y Ian Hacking como terapeuta particularmente apto para detectarlo).

En realidad, el deambular del pensamiento que acarrea una deriva sintomática y artística, tardará en encontrar su coartada, pasando por alto incluso la etapa romántica que disculpa los paseos del caminante solitario 
encarnado por Rousseau y los no por bucólicos menos vehementes extravíos en el espacio y la memoria de Wordsworth. El punto de transición parece ser Nietzsche, cuyo epistolario revela la vulnerabilidad indiscernible del cuerpo y el espíritu y, postrera, siguiente, la materia y el pensamiento capaces de producirlos (Klossowski). Ahora bien, difícilmente haya una transmisión inmediata entre la misión de Nietzsche — narrador protagonista - y el delicado pudor visible en el oficio del autor de Don Quijote, preciosamente prematuro por obra y gracia de una actividad que simulaba aliar la actitud del misionero y el temple del artesano. Como dice Luis Iglesias Feijoo: "Cervantes nos ofrece así una narración que no sólo cuenta unos hechos, sino que trata asimismo del proceso de cómo se han contado; ofrece una fábula, pero también el secreto de cómo éstas se crean; inventa la novela moderna, pero a la vez la hace nacer sabia, consciente, reflexiva ... y plena de humor"?

Pero en términos literarios, y en contra de cualquier tendencia que vaya o venga, una armonía preestablecida parece guiar a los mejores a los mismos lugares. Y así como el Ahab - monomaníaco se decía en una época- que persigue con cuidada tentación de destino a su destructor Moby Dick, Don Quijote contesta con desabrida cordura algunas de las preguntas que algunos de los cuerdos que lo rodean le formulan. Dice: "Sé donde estoy". Lo mismo que dice - "I Know where I am"- ese atenuado personaje de confín de Melville, Bartleby. Las únicas significativas después de su ceremonioso, reiterado y genial "Preferiría no hacerlo".

De qué modo la locura, atribuida ya al autor más que al personaje (como en Melville, todavía en el diecinueve), a Cervantes más que a Quijote, ha entreverado ficción y realidad, para intercalar en una otra, para redefinir su aporía, para convencernos de que uno al menos de los aspectos de la recia, intratable realidad puede conquistarse en la amable locura, no podremos averiguarlo aquí. Wystan Hugh Auden, que sigue la línea identificatoria de Ismael y Don Quijote en un libro extraño en el que compila unas lecturas más extrañas aun, llega a la misma conclusión: la busca no es estética ni artística sino religiosa. La creencia sigue siendo más poderosa que la discreta, disminuida voluntad de poder.

Don Quijote, en extrema dificultad de parangón, es todo para todos, es Shakespeare y es algo más que Shakespeare por provenir de varón mortal identificado, ajeno por completo al anonimato, incluso en pleno siglo diecisiete. En él convergen en staccato las controversias y las escasas ar-

${ }^{7}$ Don Quijote de la Mancha, edición del Instituto Cervantino 1605-2005, dirigida por Francisco Rico, Vol. Complementario (Barcelona: Galaxia Gutenberg, 2005). 
monías, los conflictos y los delirios, las falacias, las supersticiones, las creencias, los giros, las calumnias, los vértigos, las delicadas aproximaciones, los ruegos concedidos por las pasiones al entendimiento. Groussac, que considera incongruente la conducta de Don Quijote (en el capítulo de la venta, por ejemplo), Groussac, tan luego, con su servilismo positivista, va a encontrar nuevas razones para descalificar la aventura del Quijote, con las medidas y los rigores de un sastre naturalista siempre, y con su boca y su voz finita de francés educado y desperdiciado lejos de estos suburbios, dirá en conferencia, confundido: "La observación tan celebrada del caso patológico (hasta por alienistas encandilados, como el Doctor Ball): de ese delirio parcial o monomanía caballeresca - para emplear la nomenclatura anticuada pero expresiva de Esquirol— está llena de lagunas y errores". Es aquí donde Ian Hacking habla a raudales de concomitancias entre el sueño y la vigilia, entre la vigiliambulancia y el error fáctico que nos permite encontrar el camino ${ }^{8}$.

\section{Rocinante}

Rocinante es visto en el interior de la novela por Cervantes: "Estaba Rocinante maravillosamente pintado, tan largo y tendido, tan atenuado y flaco, con tanto espinazo, tan hético confirmado, que mostraba bien al descubierto con cuánta advertencia y propiedad se le había puesto Rocinante" 9 .

Américo Castro encuentra una alternativa a la locura ambulatoria. Anticipándose, predica sin saberlo una, otra alarma adicional, que parece transformarse en hipótesis de Deleuze cuando señala "el devenir animal" de los percances de Don Quijote y señala como único responsable de los mismos a Rocinante. Bastaría invocar uno de los epitafios que preceden el fin de la primera parte del libro: "Aqui yace el caballero / Bien molido y mal andante / A quien llevó Rocinante / Por uno y otro sendero" para darle la razón, y encontrar así una nueva pista para seguir al caballero de la triste figura. Y seguirlo paso a paso, casco a casco, al trote o al galope.

\footnotetext{
${ }^{8}$ De nuevo, azarosamente, las fuentes de mezclan, se comunican entre sí. El libro de Auden, Iconografía romántica del mar, traducción de Ignacio Quirarte (México: UNAM, 1996), compila unas charlas en la Universidad de Virginia para la Fundación Page-Barbour en 1949. El otro libro consultado, Mad Travelers: Reflections on the Reality of Transient Mental Illness, compila las charlas en la misma universidad y para la misma fundación de Ian Hacking en 1997. Ésta debe de ser otra de las funciones de las notas al pie, hacer que dos libros por completo distintos den a conocer sus antecedentes aquí abajo.

${ }^{9}$ Don Quijote de la Mancha (Valencia: Afrodisio Aguado, SA, Editores libreros, 23 de abril de 1956).
} 
Ha habido maneras de pensar en movimiento que interceden por este pensamiento feliz, tal vez el único, del alarmado estudioso español. Y hasta, sin abusar del ingenio — ni, Dios nos libre - de la erudición, podríamos dar con ejemplos de buenas prosas a caballo: los jinetes briosos de Von Kleist, por ejemplo, en contraposición al naturalista ecuestre recostado de Hudson, que avanza por la pampa tendido en su silla de montar, lentamente, mirando las estrellas. En el siglo pasado y en este que corre deprisa y sigue acortándolo, los pasos, los pasos más aventurados y prodigiosos fueron dados de espaldas a la certidumbre, de espaldas a su incondicional grieta. No estamos capacitados para establecer la diferencia de calidades, en filosofía, por ejemplo — de Nietzsche vertical, nervioso, a Wittgenstein igualmente nervioso, en horizontal, aplomada meditación y reposo-, pero la longevidad espuria - moderna - de la novela ha establecido claves de quietud, estabilidad, y fuga, movimiento, que no siempre fueron asimiladas por los críticos. "Ma ligne de chance, ma ligne de anche", en la voz de Ana Karina en Pierrot le fou, tarareada con mayor o menor éxito en los libros de Deleuze, celebra como un cumpleaños sin ombligo las nupcias postergadas de la novela con el azar a solas, con el azar a cuestas.

Cervantes había tenido ya la precaución de pensar un precursor: Cide Hamete Benengeli que podía cambiarle la edad a la historia, al relato, a la novela, al revelar su precedencia, su sangre, su devoción adversa, su cuidado por el detalle.

La creación, inspirada tal vez por la falta de alevosía, de Cide Hamete Benengeli que permite leer como escrito el Quijote da a las peripecias y aventuras del caballero enjuto una hondura insólita.

Antes de ser aprendido y domesticado por la gramática peatonal del siglo veinte y sus variantes new age, caminar a solas, a secas, recorriendo el mundo, tuvo una leyenda y una épica. En un ensayo extraordinario, exquisito sobre la convalecencia, Lamb, Charles Lamb, que tanto hizo por hacer el tonto y no llamar la atención ("ese triste par de fenómenos", llamaba a él y a su hermana Carlyle, por el momento dueño de la historia), llama la atención sobre este estado anterior a la embriaguez de caminar, y la adicional, que es el pensar doliéndose nietzscheano (afinado a partir de esos preparativos, ese deambular, esos provisionales lugares eternos con que un estadio previo a la enfermedad encuentra la prosa de cámara capaz de proteger los más nimios pensamientos para que despierten a buen recaudo dos o tres días después, a disposición de la buena salud o de la enfermedad, sanos y salvos ellos, fuera del cuerpo, unos pocos dolores más). La licencia de Hazlitt y Stevenson, pensadores postreros directos y estrictos del caminar, atentos a esa distancia que guarda la ocurrencia del aforismo, el balbu- 
ceo de la meditación, no cierra una aventura en círculo, posterga simplemente la dirección incierta de la caminata. Un mundo de certezas no es más rico que el mundo cuya riqueza consiste en la ambigüedad.

El Quijote está fuera de Don Quijote, y Cervantes dentro, como hemos visto (gracias a Dios, a Cervantes, a Borges, a Cide Hamete Benengeli, a Pierre Menard). Por penetrantes que intentáramos ser, por profundamente originales, Don Quijote gana la pulseada, la contienda, la apuesta: permanece afuera de esa órbita constrictora que la crítica ha inventado para no eximir a sus deudores, para que los evasores padezcan el peor castigo, la condena más dura. Aun cuando pretendiéramos dar vuelta todo, la sabiduría de Cervantes ha previsto estas cautelas y atenuantes con ensordecedora, elocuente anticipación. Y la vehemencia de los dos personajes - distinta, convexa, inagotable - y la de todos los que acompañan, ha consolidado el mundo que nosotros, como lectores, haríamos mal en pasar por alto. Cervantes le da a la novela el lugar —el espacio se dice- de un espectáculo continuo (de ahí el "más y más" que Amis no entiende), y a la asistencia de los lectores el privilegio ceremonioso de descubrir la decisiva batalla del mundo. Al revés de lo que nos han hecho creer las obras maestras nacionales precedentes — ¿vale la pena enumerarlas?-, pero no todos los clásicos, Don Quijote no puede rematarse con una conjunción, un sínodo o un convenio de sustantivos abstractos. No se trata del diálogo de la razón y la locura, de la sensatez y la irracionalidad, de la cordura y el delirio. Es mucho más sencillo que eso. Con siglos de atraso, esa lección ha sido entendida, en gran medida gracias a las tentaciones de la dictadura del raciocinio, con el impuesto de la necesidad incluido sobre las tentaciones de la gratuidad del instinto en su contra gracias a la novela como ejercicio persuasivo.

Sin embargo, ¿cuánto se puede sostener un pensamiento?

Porque un pensamiento no es sólo un término conciliatorio cuando termina el día, el momento en el que las causas del hombre de pie, del caminante que vuelve al hogar, depone sus fantasías - su idealismo- en aras de una conformidad constitutiva contra las violencias reales del mundo, sino el perplejo ajuste - siempre tardío - del acto contra los pensamientos del mundo, obra de hechiceros enemigos. En ese sentido, Don Quijote es perfecto: contra la virulencia excesiva del mundo real, las armas (y hasta las armas secretas sin nombre hasta entonces) de lo que habían dado en llamar (sin saber que se trataba de la literatura) la imaginación (cuando por precaución y elegancia nos precave de que el Quijote que leemos no es un invento propio). 
La otra pregunta que parece formular en un aparte teatral Cervantes, y la que responde con vehemencia en más de mil páginas, fingiendo contar una historia, es otra: la misma. Porque contar una historia acaso sea sostener un pensamiento. Es cierto en un comienzo, "En un lugar de la Mancha..." Y en cuanto sigo "de cuyo nombre no quiero acordarme..." Parece debilitarse cuando uno dice "rocín flaco, galgo corredor", pero es mentira, ¿quién creería sin pruebas? Para bien de unos y otros, lectores todos, sólo queremos seguir materialmente con el hilo de esta historia.

$\mathrm{Y}$ un pensamiento puede seguirse todo lo que uno quiera si lo sostiene la acción y la representación. Cervantes, agente espía de la contrarreforma en nuestros oídos ateos, lo sabe mejor que cualquiera. Antes.

Por suerte, el Quijote le llevó tanto tiempo que le impidió seguir practicando el arte aprendido en el ejercicio de hacerlo, oficio que termina manufacturando "mamarrachos de perfección". Así llamaremos a Los trabajos de Persiles y Segismunda, son tan distintos que muchos (Borges incluido) lo consideran ajeno.

\section{Accidentes inseparables}

De qué manera genial, intrincada, indicadora de su genio de acuñación estilístico inmediata, tan distinto del de sus contemporáneos, Cervantes registra el mundo que lo rodea precediéndolo. Prescindamos de ejemplos narrativos.

El asombroso, opaco y deliciosamente disimulado "accidentes inseparables" de La gitanilla es uno de los ejemplos que disimuladamente se nos ofrece, que obstinadamente prefiero. Porque, ¿de qué modo este filósofo tan distinto y distante de los demás que es Miguel de Cervantes Saavedra - de Parménides a Séneca, de Miguel de Molinos a Santayana - se las arregla para diferir, demorar, diferenciarse? Ya hemos visto que Auden dice en su ensayo que el Quijote es un héroe religioso, pertenece por su fe a este ordenamiento, a esta categoría. Detectar entre el anhelo y la acción, entre "la gana de hurtar y el hurtar", esta terrible definición de "accidentes inseparables" excede cualquiera de las aproximaciones al presente de la obra maestra. "Accidentes inseparables", la categoría cervantina puesta casi sin fe en el comienzo de La gitanilla revela cómo algunas de las partículas de nuestra memoria de la literatura española —el "apúrate que me muero, carcelero", de Juan del Encina, "el no sé qué que andan balbuciendo", de San Juan de la Cruz, "el babeo de asco de mi nada", de Santa Teresa, el "de manera que una sola palabra se diga entre un anhelito y otro, y mientras 
durare el tiempo de un anhelito a otro", de Ignacio de Loyola - conforman un tejido de relaciones suspendido sobre la lengua que nos mantiene alertas, unidos. Sólo que esta fórmula que Cervantes susurra no tiene el esplendor en arco de sus catecismos narrativos sino una entonación íntima y abstracta. Opaca, enigmática, sofocada.

Ahora bien, "inseparables" no presenta dificultad alguna de entendimiento. Pero, ¿qué significa ese "accidentes” que la precede, puesto ahí con tanta certidumbre? Como no puedo recurrir al español contemporáneo de Cervantes, a Covarrubias, vamos a dar una vuelta inicial.

Cervantes no parece - aunque sí, aunque tal vez sí- utilizar la categoría filosófica, aristotélica, de acuerdo con la cual "accidente es lo que puede pertenecer a una sola y misma cosa, sea la que fuere...", o "lo que pertenece a un ser y puede ser afirmado de él en verdad, pero no siendo por ello ni necesario ni constante" (Metafísica), definición de la que nos gustaría conservar ese final: "ni necesario ni constante". En diccionarios más jóvenes que el de Covarrubias, podemos enterarnos sin asombro cómo en la raíz etimológica de "accidente" está parcializado un sentido importante - caer-, pero después de desechar no menos de tres frugales suministros cuerdos, encontramos esta quinta acepción del DRAE, que se adecua con gusto a esa "gana de hurtar y hurtar" hermanados como "accidentes inseparables". Esta quinta acepción es en sí misma una sinfonía de sentidos: "pasión o movimiento del ánimo". Sí, la ambición de verbo y el verbo se alcanzan y se equidistan y se equivalen porque son pasiones o movimientos del ánimo, accidentes involucrados en la tarea de volver misteriosa nuestra laberíntica afrenta a los dioses, que tiznan, tiñen y confunden todo lo que a su paso queda. Y que, ni necesarios ni constantes, burlan todas las tiranías, todas las estrecheces, todos los cadalsos.

Porque "accidentes inseparables" es la medida capaz de protegernos de lo que no conocemos. Si acariciáramos esta categoría - y no hay medida capaz de impedírnoslo-, ésta podría llevarnos por el camino del exceso, si bien no al palacio de la sabiduría, al cuantioso reino del azar, a ese azar que es el de los jardines que se bifurcan, pero además, pero también el de la biblioteca de Babel y el de la lotería en Babilonia, sobre todo el espaciado azar que permite la comunicación de un capítulo de Cervantes con una asombrosa transcripción taquigráfica, tautológica, reveladora de la vengativa fase del eterno regreso y también de la inmensa posibilidad amnésica de reencontrarla, que el pensamiento del camino, el aforismo, el quasi adagio, como contrapartida al regreso inmediato, prosaico del refrán, ha rechazado con súbito e incansable desdén. 
Por eso los accidentes inseparables de Cervantes son emisores de infinitas series equivalentes al súbito desdén, a "la expulsión de la abyecta tentación de fracaso". Contra la postración, la prosternación, el duermevela, la vigilia de ojos abiertos, la convalecencia, la prosa adormecida, lánguida, Cervantes antepone el pensamiento del camino y de la adarga vertical, el pensamiento del tropiezo. Una vez lanzado, proferido un lugar de la Mancha, lo mejor que podrá pasarle a este caballero de fijado destino será ignorarlo para sintonizar, no la serie de aventuras, percances (más, siempre más), sino, apto de su orgullo, su idealismo, su dignidad, sus apostasías, el encuentro con la elaboración de azar que esta fuerza direccional tiene que - necesariamente - convocar a su alrededor. Por eso, como contrapartida gratuita, "la adarga fina", "el galgo corredor", "los duelos y requiebros" no sólo forman racimos de nítida percepción como los que Ireneo Funes podía evocar, sino lapsus, olvidos intrigantes entre partes de la serie tan graves que no queda más remedio que reconstruir el Quijote cada vez que decidimos olvidarlo.

Parte esencial de la memoria del mundo, de toute la mémoire $d u$ monde, museo de su encapsulada y convencional manera de clasificar - domesticar, disecar - la literatura, pero también de la inmensa energía capaz de destruirla, Don Quijote es tal vez la obra occidental capaz de cambios más exasperantes y extemporáneos (tal como lo advirtió Menard) y por lo tanto la más apta para seguir abriendo y trazando caminos

Además, la confortable fórmula final, digna también del colofón de una liturgia, tiene una impensada salida de emergencia, un plan B, un plan de evasión sin clave de naufragio. Porque es propio de la clandestinidad inherente al proyecto de cualquier creación verdadera, al que se adhiere lógicamente como souvenir la destrucción (esa aparente violencia que los aprendices de hechiceros de diversas y sucesivas vanguardias canjearon por máscaras cada vez mejor adaptadas a la conformidad y el sometimiento). Y ésta es la que prolonga para siempre la belleza accesoria de los "accidentes inseparables", su noble causa sin proporciones, su indisputable arte consagrado a separar el azar de la necesidad.

Para estos "accidentes inseparables" no hay reparación posible, no hay bálsamo, licor extremado de Fierabrás. Son accidentes e inseparables para siempre. Son Don Quijote y Sancho, Rinconete y Cortadillo, Montescos y Capuletos, Ismael y Ahab, Tom y Huck, Bouvard y Pécuchet, Mutt y Jeff, Beavis y Butthead. Menos parejas obstinadas en dar crédito a la alegoría de la amistad, menos dualidades funcionales en pos de una apariencia, menos paradojas atoradas, menos incluso separaciones íntimas inevitables 
que inevitables opuestos alineados para que la serie, la línea —ma ligne de anche ma ligne de chance- encuentre en el mundo su exclusiva entrega triunfal a esa intolerable ficción llamada realidad. 